\title{
Interactions between cortisol and lipids in human milk
}

\author{
Kaisa M. Linderborg ${ }^{1^{*}}$ (D), Maaria Kortesniemi ${ }^{1}$, Anna-Katariina Aatsinki ${ }^{2}$, Linnea Karlsson ${ }^{2,3}$, Hasse Karlsson ${ }^{2,4}$, \\ Baoru Yang ${ }^{1}$ and Henna-Maria Uusitupa ${ }^{2}$
}

\begin{abstract}
Background: Human breast milk is one of the key early postnatal biological exposures for the developing child. It includes bioactive compounds, such as cortisol and fatty acids, which may be linked via the mother's lipid metabolism.

Methods: This study investigated the associations between cortisol and lipids in human milk at the infant age of 2.5 months. Human milk cortisol concentrations were measured using luminescence immunoassay, and two groups of milks ( $n=50$ each) were formed based on either high ( $>10 \mathrm{nmol} / \mathrm{L})$ or low $(<3 \mathrm{nmol} / \mathrm{L})$ cortisol levels. Lipids, as fatty acid content and composition of neutral (triacylglycerol-rich) and polar (phospholipid-rich) lipids, were measured with gas chromatography. The samples originated from the FinnBrain Birth Cohort Study.

Results: The percentage of phospholipid-rich lipids of total lipids was $33.08 \% \pm 1.33 \%$. In triacylglycerol-rich lipids, high cortisol level in milk was associated with higher lauric (12:0, mass $\%$ and $\mathrm{mg} / \mathrm{mL}$ ), myristic (14:0, mass \% and mg/mL), eicosenoic (20:1n - 9, mass \%), docosenoic (22:1n - 9, mass \%, and $\mathrm{mg} / \mathrm{mL}$ ) acids, and to lower palmitic acid (16:0, mass \%) compared with low cortisol levels in milk. In phospholipid-rich lipids, high cortisol level was associated with higher myristic (14:0, mass \%) and docosenoic (22:1n - 9, mass \%) acids. After adjusting for pre-pregnancy BMl and sampling time by linear regression, the milk cortisol remained a significant predictor for lauric and myristic acids in triacylglycerolrich lipids, and myristic and docosenoic acid in phospholipid-rich lipids ( $\beta=0.23$ to 0.38 and $p<0.05$ for each).
\end{abstract}

Conclusions: This study revealed certain significant associations between milk cortisol and the fatty acid composition of human milk, indicating that cortisol might be one of the factors affecting the origin of the lipids in human milk.

Keywords: Cortisol, Fatty acids, Human milk, Lipids, Phospholipids, Triacylglycerols

\section{Background}

\section{Plasma and milk cortisol and cortisol's effects on lipid} metabolism

Human breast milk contains a number of bioactive compounds, and thus it serves as one of the key early postnatal biological exposures for the developing child. Bioactive constituents in human milk include cortisol, fatty acids (FAs), such as polyunsaturated fatty acids (PUFAs), and parts of the milk fat globule membrane. These are all

\footnotetext{
*Correspondence: kaisa.linderborg@utu.fi

'Department of Biochemistry, Food Chemistry and Food Development, University of Turku, Itäinen Pitkäkatu 4C, Fl-20014 Turun yliopisto, Turku, Finland

Full list of author information is available at the end of the article
}

linked, as the metabolic and endocrine activities of adipose tissue, and energy metabolism in general, are affected by glucocorticoids, cortisol and cortisone [1]. Both cortisol and cortisone are secreted from the cortex of the adrenal glands in response to physiological and psychological stress [2]. Of these, especially cortisol plays a key role in gluconeogenesis, lipolysis and energy metabolism and thus potentially affects the lipid content and composition of human milk. Acutely, cortisol may play a role in the utilization of different lipid sources for the production of the lipids of human milk [3-6], while chronic exposure to cortisol has been linked with lipogenesis and obesity [7]. The linkage between lipids and cortisol may be mediated

(c) The Author(s). 2020 Open Access This article is licensed under a Creative Commons Attribution 4.0 International License, which permits use, sharing, adaptation, distribution and reproduction in any medium or format, as long as you give appropriate credit to the original author(s) and the source, provide a link to the Creative Commons licence, and indicate if changes were made. The images or other third party material in this article are included in the article's Creative Commons licence, unless indicated otherwise in a credit line to the material. If material is not included in the article's Creative Commons licence and your intended use is not permitted by statutory regulation or exceeds the permitted use, you will need to obtain permission directly from the copyright holder. To view a copy of this licence, visit http://creativecommons.org/licenses/by/4.0/ The Creative Commons Public Domain Dedication waiver (http://creativecommons.org/publicdomain/zero/1.0/) applies to the data made available in this article, unless otherwise stated in a credit line to the data. 
via cytokines. Adipose tissue can secrete pro-inflammatory cytokines and stimulate the hypothalamic-pituitary-adrenal axis, and cortisol decreases the production of cytokines and other inflammatory mediators $[8,9]$. The use of antenatal corticosteroids may increase the total lipid content in human milk following premature birth $(<34$ gestational weeks) [10], which further substantiates the need for investigations into the relationship between milk cortisol and milk lipids. Milk cortisol, on the other hand, has been shown to significantly correlate with the mother's plasma cortisol [11]. The role of milk glucocorticoids in infant development is not fully understood as yet, but it has been suggested that they are involved in neural development, intestinal maturation, development of microbiota and programming the infant metabolism $[12,13]$ as well as temperament traits that describe individual differences in emotional reactivity and self-regulation [14]. It has also been indicated that glucocorticoid and bile acid metabolism are linked, and that glucocorticoids play a role in the development of diseases related with obesity such as liver diseases and hypertension [7, 15]. While the composition of human milk is previously known to be influenced by gestational age [10], geographical origin [16, 17], dietary habits $[10,18-21]$, maternal body mass index (BMI) [20], socioeconomic situation [22] and even infant gender [23], there is scarce knowledge about the associations between cortisol and the lipid composition in human milk. However, milk cortisol has been shown to positively correlate with the fat content of the milk of rhesus monkeys (Macaca mulatta) [24], but in humans no association between the total fat content in milk and milk cortisol has been established [25].

\section{Origin of milk lipids and their importance for the infant}

Lipids in breast milk or infant formula are the major sources of energy and the sole supply of essential FAs to the infant during the first months of its life. Breast milk contains a complex mixture of different lipids with a quantitative dominance of triacylglycerols (TAGs). The FAs used by the mammary gland for the synthesis of TAGs originate from the mother's diet, mother's FA stores, or from the mother's de novo lipid synthesis. The milk-fat globule membrane, consisting mainly of phospholipids (PLs), pinches off from the mother's cell membrane [26]. The lipid content and composition in the mother's diet as well as the mother's dietary pattern influence the utilization of FAs for TAG synthesis by the mammary epithelial cells [27]. De novo lipogenesis is the endogenous synthesis of FAs. Increased production of TAGs by de novo lipogenesis increases the prevalence of mediumchain FAs in milk. Thus, medium-chain FAs are more abundant in the milk produced by mothers who eat a very low fat but adequate calorie diet compared to mothers on a diet containing about $40 \%$ of calories as fat [15]. Existing lipid stores are utilized especially during the mother's fasting state or in the absence of dietary fat [27]. Humans can synthesize saturated and monounsaturated FAs, while the essential FAs, linoleic $(18: 2 n-6)$ and $\alpha$-linolenic (18: $3 n-3)$ acids, must originate from the diet. PUFAs, such as arachidonic (20:4n-6), eicosapentaenoic (20:5n-3) and docosahexaenoic $(22: 6 n-3)$ acids, originate from the elongation and desaturation of the essential FAs or directly from diet, most importantly from marine sources. Although the crucial need of bioactive long-chain PUFAs for the normal development of the infant is scientifically established [28-30], the optimal composition of breast milk lipids remains unknown.

In enterocytes, lipids originating from the diet are packaged into chylomicrons, which are further secreted into blood via the lymphatics to deliver their fat to mammary glands during lactation. In addition to chylomicrons, very low-density lipoproteins originating from the liver carry abundant quantities of TAGs. In order for the TAGs of chylomicrons or very low-density lipoproteins to be transported from the circulation to the milk, they must be hydrolyzed by lipoprotein lipase. Mammary adipocytes have been suggested to be the source of lipoprotein lipase in the mammary gland [31], possibly further explaining associations between the mother's lipid metabolism and the composition of human milk.

The date of the last literature search on the topic was January $4^{\text {th }}, 2020$ by using the key words breast milk, cortisol, fatty acids, human milk, lipids, phospholipids and triacylglycerols.

\section{Aims of the study}

To better understand the factors affecting the composition of human milk, we investigated the associations of milk cortisol with the FA content and the composition in two different lipid classes, the TAG- and PL-rich lipids of human milk.

\section{Methods \\ Participants and breast milk collection}

FinnBrain Birth Cohort Study is an on-going, intergenerational prospective observational study conducted at the University of Turku, Finland. Mothers were recruited to the FinnBrain Birth Cohort Study [32] during their first trimester ultrasound visit by a research nurse. Of the baseline characteristics, parity, education level (grouped as "Mid/Low" [levels 1-5 in the Finnish education system, secondary school/vocational education or lower], "High/ Voc" [level 6: polytechnic education], "High" [levels 7-9: university/graduate school]) and exclusivity of breastfeeding were self-reported. Diagnosis of gestational diabetes, pre-pregnancy BMI, birth mode, gestational age at birth, child's birth weight, sex and mother's age were obtained from the Finnish Medical Birth Register, maintained by the Finnish National Institute for Health and Welfare, 
Finland. Medication was not considered as an exclusion criteria. From the larger FinnBrain Birth Cohort Study [32], Finnish mothers who breastfed their infants were recruited by phone calls to the early nutrition and feeding behavior sub-study (Fig. 1). A total of 733 mothers were contacted and 618 reached. Of these, 454 agreed to participate in the sub-study, and 448 gave a breast milk sample at the infant age of 2.5 months. The milk samples were self-collected by mothers in the presence of a study nurse during a study visit in the research facility. The 100 samples were collected as follows: Year: 50 samples were collected in 2014, 49 in 2015 and one in 2016. For the time of the year: 22 samples were collected in winter (January to February), 33 in spring (March to May), 21 in summer (June to August) and 24 in autumn (September to December). Weekday: on Monday, 4 samples were collected; on Tuesday, 21 were collected; on Wednesday, 33 were collected; on Thursday, 16 were collected; and on Friday, 26 were collected. Visits during the afternoon were encouraged to minimize the effect of diurnal variation in cortisol. Sampling time is presented as minutes after 8:00 am in Table 1, and it was used as a covariate in statistical analyses. The mothers were instructed to feed the baby from the right breast $1.5-2 \mathrm{~h}$ prior to the study visit and thereafter refrain from feeding from the right breast before taking the study sample. Breastfeeding from the left breast was not restricted. After entering the research facility mothers were asked to wear latex gloves and express 10 $\mathrm{mL}$ of front milk with manual expression from the right breast. The samples were immediately transferred to and kept in $\mathrm{a}-70{ }^{\circ} \mathrm{C}$ freezer until analyzed. For the present study, two subpopulations of fifty mothers each were drawn from the population, who had given breast milk samples based on the milk previously determined [14] milk cortisol levels $(<3 \mathrm{nmol} / \mathrm{L}$, mean $\pm \mathrm{SD}=2.02+/-$ 0.44 or $>10 \mathrm{nmol} / \mathrm{L}$, mean $\pm \mathrm{SD}=15.2 \pm 5.89 \mathrm{nmol} / \mathrm{L})$ in order to investigate differences in lipid content based on milk cortisol groups. The baseline characteristics of the dyads are presented in Table 1.

\section{Milk cortisol}

Milk was thawed at room temperature and gently mixed for $1 \mathrm{~min}$ prior to dichloromethane extraction. Cortisol was analyzed using a validated luminescence immunoassay method (IBL International, product RE62111) [33] at the Finnish Institute of Occupational Health. Values are expressed as nmol/L.

Fatty acid content and composition of triacylglycerol-rich and phospholipid-rich fractions of milk

The FA compositions of neutral lipid (i.e., the TAG-rich fraction) and polar lipid (i.e., the PL-rich fraction)

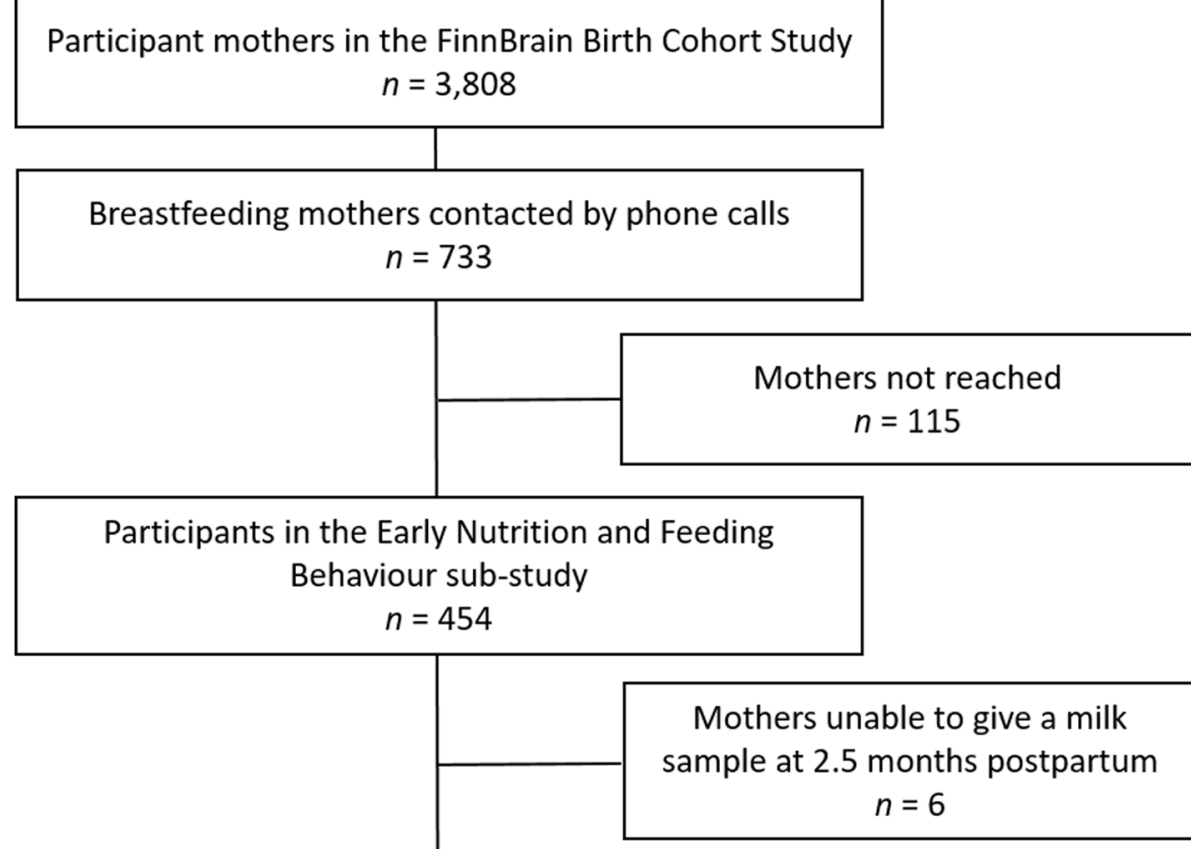

$$
\begin{aligned}
& \text { A subsample drawn for breast milk lipid analysis } \\
& n=50 \text { (with the highest measured milk cortisol) } \\
& n=50 \text { (with the lowest measured milk cortisol) }
\end{aligned}
$$

Fig. 1 Flow chart of the study participants and design 
Table 1 Characteristics of the mother-infant dyads by low and high milk cortisol groups

\begin{tabular}{|c|c|c|c|c|c|}
\hline & $\begin{array}{l}\text { Whole population } \\
(n=100)\end{array}$ & $\begin{array}{l}\text { Low milk cortisol <3 } \\
\mathrm{nmol} / \mathrm{L}(n=50)\end{array}$ & $\begin{array}{l}\text { High milk cortisol > } 10 \\
\mathrm{nmol} / \mathrm{L}(\mathrm{n}=50)\end{array}$ & T-test $^{a} / X^{2}$ & OR $(95 \% C l)^{b}$ \\
\hline Gestational age & $40[36-42]$ & $40[36-42]$ & $40[37-42]$ & $\begin{array}{l}\mathrm{t}=-1.49(p= \\
0.14)\end{array}$ & \\
\hline Infant gender & & & & $\begin{array}{l}x^{2}=0.16(p= \\
0.67)\end{array}$ & $1.28(0.58,2.81)$ \\
\hline Boy & $55(55 \%)$ & $29(58 \%)$ & $26(52 \%)$ & & \\
\hline Girl & $45(45 \%)$ & $21(42 \%)$ & $24(48 \%)$ & & \\
\hline Birth mode & & & & $\begin{array}{l}x^{2}=0.08(p= \\
0.77)\end{array}$ & $0.72(0.23,2.24)$ \\
\hline Vaginal delivery & $86(86 \%)$ & $44(88 \%)$ & $42(84 \%)$ & & \\
\hline Cesarean section & $14(14 \%)$ & $6(12 \%)$ & $8(16 \%)$ & & \\
\hline Mother's BMI & 24 [18-39] & 25 [19-39] & 24 [18-37] & $\begin{array}{l}\mathrm{t}=1.74(p= \\
0.09)\end{array}$ & \\
\hline Mother's age & $30[24-44]$ & $31[24-44]$ & 30 [24-37] & $\begin{array}{l}t=2.24(p= \\
0.03)\end{array}$ & \\
\hline Education level & & & & $\begin{array}{l}x^{2}=1.26(p= \\
0.53)^{c}\end{array}$ & \\
\hline $\begin{array}{l}\text { Secondary school / vocational } \\
\text { education or lower }\end{array}$ & $22(22 \%)$ & $12(24 \%)$ & $10(20 \%)$ & & \\
\hline Polytechnic & $38(38 \%)$ & $17(34 \%)$ & $21(42 \%)$ & & \\
\hline University/graduate school & $33(33 \%)$ & $19(38 \%)$ & $14(28 \%)$ & & \\
\hline Missing data & $7(7 \%)$ & $2(4 \%)$ & $5(10 \%)$ & & \\
\hline Primiparous & & & & $\begin{array}{l}x^{2}=2.69(p= \\
0.10)\end{array}$ & $2.15(0.95,4.90)$ \\
\hline No & $39(39 \%)$ & $24(48 \%)$ & $15(30 \%)$ & & \\
\hline Yes & $61(61 \%)$ & $26(52 \%)$ & 35 (70\%) & & \\
\hline Gestational diabetes & & & & $\begin{array}{l}x^{2}=2.82(p= \\
0.09)\end{array}$ & $3.24(0.96,11.00)$ \\
\hline Yes & $15(15 \%)$ & $11(22 \%)$ & $4(8 \%)$ & & \\
\hline No & $85(85 \%)$ & $39(78 \%)$ & $46(92 \%)$ & & \\
\hline Exclusive breastfeeding & & & & $\begin{array}{l}x^{2}=0.9(p= \\
0.34)\end{array}$ & $0.48(0.15,1.56)$ \\
\hline No & $14(14 \%)$ & $5(10 \%)$ & $9(18 \%)$ & & \\
\hline Yes & $84(84 \%)$ & $45(90 \%)$ & $39(78 \%)$ & & \\
\hline Missing data & $2(2 \%)$ & $0(0 \%)$ & $2(4 \%)$ & & \\
\hline Birth weight & 3656 [2705-4940] & 3622 [2830-4940] & 3690 [2705-4660] & $\begin{array}{l}t=-0.69(p= \\
0.49)\end{array}$ & \\
\hline $\begin{array}{l}\text { Milk cortisol concentration (nmol/ } \\
\text { L) }\end{array}$ & $9[1-34]$ & $2[1-3]$ & $15[10-34]$ & $\begin{array}{l}\mathrm{t}=-15.81 \\
(p<0.001)\end{array}$ & \\
\hline $\begin{array}{l}\text { Sampling time as minutes after } 08 \text { : } \\
00 \mathrm{am}\end{array}$ & 319 [30-645] & 354 [120-645] & 284 [30-555] & $\begin{array}{l}\mathrm{t}=2.93(p= \\
0.004)^{\mathrm{d}}\end{array}$ & \\
\hline Infant age at sampling (days) & $61[41-106]$ & $60[41-85]$ & $62[46-106]$ & $\begin{array}{l}t=-0.94(p= \\
0.35)\end{array}$ & \\
\hline
\end{tabular}

Data is given as mean or number with either range in square brackets or percentage in parentheses

a $\mathrm{df}=98$

${ }^{b}$ Crude odds ratio with $95 \%$ confidence interval

${ }^{c} \mathrm{X}^{2}$ for trend: Linear-to-linear association $0.13, \mathrm{df}=1, p=0.719$

${ }^{d}$ Data available from 47 dyads in the low cortisol group and 46 dyads in the high cortisol group $(\mathrm{df}=91)$ 
fractions were analyzed from each sample in duplicate. Samples were thawed at room temperature and gently mixed, after which the internal standard mixture consisting of triheptadecanoin (Larodan Fine Chemicals $A B$, Malmö, Sweden) and dinonadecanoylphosphatidylcholine (Larodan Fine Chemicals AB, Malmö, Sweden) was added to the sample. The total lipids were extracted from samples with a modified Folch procedure [34] with chloroform, methanol and $0.88 \%$ potassium chloride in water in a two-phase extraction to maximize the yield. Extracted lipids were further separated into TAG-rich and PL-rich fractions by solid phase chromatography using silica cartridges (Waters, Dublin, Ireland) [35]. The TAG-rich fraction was eluted from the column with high-performance liquid chromatography grade dry diethyl ether (Merck KGaA, Germany) and the PL-rich fraction with high performance liquid chromatography grade methanol (Honeywell, Riedel-de Haen, France). Fatty acid methyl esters were prepared from the isolated fractions with sodium-methoxide-catalyzed transesterification. The methyl esters were analyzed with Shimadzu GC-2010 with an AOC-20i auto injector and flame ionization detector and GCsolution software (Shimadzu Corp., Kyoto, Japan). Splitless/split injection with a split opened after $1 \mathrm{~min}$ was used. A wall coated, open tubular column DB-23 $(60 \mathrm{~m} \times 0.25 \mathrm{~mm}$ i.d., liquid film $0.25 \mu \mathrm{m}$, Agilent Technologies, J.W. Scientific, Santa Clara, CA, USA) was used to separate the methyl esters. The following settings were used: injector at $270^{\circ} \mathrm{C}$, oven initial at $130^{\circ} \mathrm{C}$, hold $1 \mathrm{~min}$, rate $4.5^{\circ} \mathrm{C} / \mathrm{min}$ to $170^{\circ} \mathrm{C}$, hold $0 \mathrm{~min}$, rate $10^{\circ} \mathrm{C} / \mathrm{min}$ to $220^{\circ} \mathrm{C}$, hold 14.5 min, rate $60^{\circ} \mathrm{C} / \mathrm{min}$ to $230^{\circ} \mathrm{C}$, hold $3 \mathrm{~min}$ and detector at $280^{\circ} \mathrm{C}$. Helium was used as carrier gas and $68 \mathrm{D}(\mathrm{Nu}-$ Check-Prep, Elysian, MN, USA), Supelco 37 Component Fatty Acid Methyl Ester Mix (Supelco, St. Louis, MO, USA), and 11A (Nu-Check-Prep, Elysian, MN, USA) as external standards. Results were expressed as molar percentage of each FA in its lipid category and as $\mathrm{mg}$ in $\mathrm{mL}$ milk. Additionally, the percentage of polar lipids (as phosphatidylcholines) from all lipids was calculated. The quantity $(\mathrm{mg} / \mathrm{mL})$ is presented as indication of the absolute amount of FAs received by the infant. However, human milk is known to vary in its lipid content even within the same feeding. Thus, relative proportions (percentages of certain FAs of all FAs), which are an indication of the FA balance within the different FA families (SAFAs, MUFAs, omega-3 PUFAs and omega-6 PUFAs), are also presented. Fatty acids were named both with their common names as well as the systematic numeric abbreviation. The latter represents the number of carbons in the acyl chain followed by the number of double bonds in the acyl chain as well as the location of the first double bond from the omega end of the acyl chain, for example oleic acid (18:1n-9). Quantification was based on internal standards. Odd numbered FAs were chosen as internal standards, as their chromatographic behavior is similar to that of even numbered FAs, but they are not expected to be present in the milk lipids in substantiated amounts.

\section{Statistical methods}

Statistical analyses were performed with the SPSS version 23 program (IBM, Armonk, NY, USA). Multivariate models were performed by using Unscrambler $\mathrm{X}$, version 10.4 (CAMO Software, Oslo, Norway). All data were checked for normality and homogeneity of variance and reported as means \pm standard deviation. Statistical significance was determined at $p<0.05$. Independent samples T-test or Mann-Whitney $U$ test, depending on the normality of the data, was used to assess significant differences between the high and low cortisol groups. A Pearson Chi-Square and odds ratios were used for categorized variables. Principal component analysis (PCA) was applied for standardized data to study the differences and possible classifications among samples. Cross validation was used to estimate the number of components for a statistically reliable model. Linear regression models were built for the lipids to adjust milk cortisol for the pre-pregnancy BMI and milk sampling time. For these models, milk cortisol (as a continuous variable) was transformed to its natural logarithm, and missing values for sampling time $(n=7)$ were imputed with mean value of the other cases.

\section{Results}

\section{Characteristics of the mother-infant dyads}

There were no differences in the gestational age, birth weight, infant age at the milk sampling time, infant gender, vaginal delivery, education level, parity, or exclusivity of breastfeeding between the groups formed based on milk cortisol levels (Table 1). Low milk cortisol was associated with higher pre-pregnancy BMI when compared with high milk cortisol, and there was a significant difference in the sampling time measured as minutes after 8:00 am between the low and high cortisol groups $(\mathrm{t}=$ $2.93, \mathrm{df}=91, p=0.004 ;$ mean $\pm \mathrm{SD}=354 \pm 119$ vs. $284 \pm$ 108 min, respectively; Table 1). Only two of the mothers reported themselves as smokers.

\section{Fatty acid content and composition of triacylglycerol-rich and phospholipid-rich fractions}

Results expressed as $\mathrm{mg} / \mathrm{mL}$ deviated more from sample to sample than relative proportions (\% of all FAs in TAG-rich and PL-rich fractions) due to the expected variation [26] in the lipid content of human milk (Table 2, Table 3). The content of TAG-rich or PL-rich lipids did not differ between the groups formed. 
Table 2 Fatty acid compositions of triacylglycerol-rich lipids in human milk

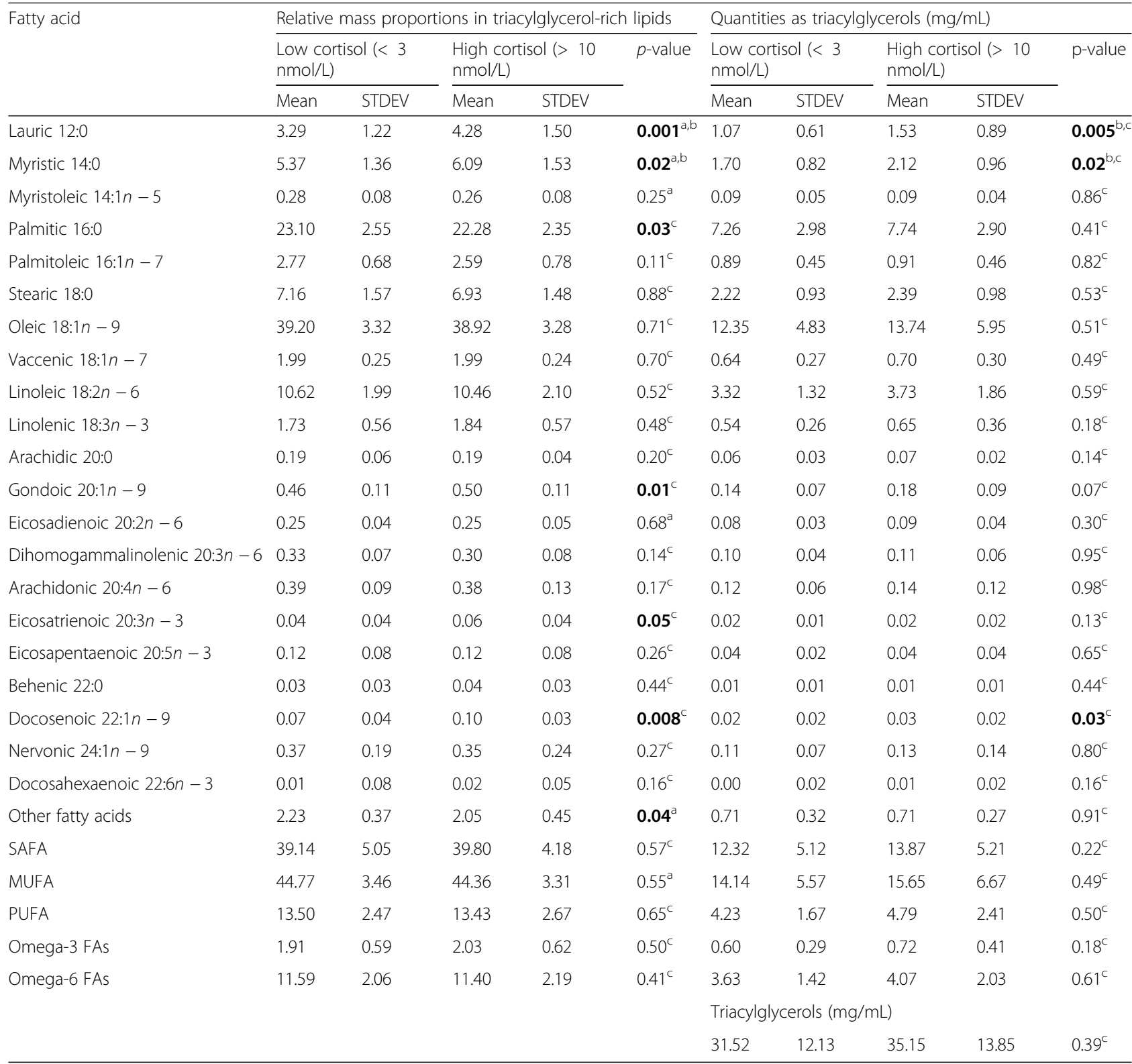

Data is presented as relative proportions $(\%)$ and quantities $(\mathrm{mg} / \mathrm{mL})$ and grouped based on milk cortisol levels. Statistically significant differences $(\mathrm{p}<0.05)$ between low and high milk cortisol groups are highlighted with bold type. Abbreviations: STDEV standard deviation, SAFA saturated fatty acids, MUFA monounsaturated fatty acids, PUFA polyunsaturated fatty acids

${ }^{\text {a }}$ Significant difference between the low and high cortisol groups, T-test $(\mathrm{df}=98)$

${ }^{\mathrm{b}}$ Milk cortisol (as continuous variable) remained a statistically significant predictor after controlling for pre-pregnancy BMI and sampling time in linear regression analysis, see Additional file 1

' Significant difference between the low and high cortisol groups, Mann-Whitney $U$ test

\section{Lipid and cortisol interactions}

Among the TAG-rich lipids (Table 2), monounsaturated FAs (MUFAs) were most abundant in mass proportion (\%) and they consisted mainly of oleic acid, $(18: 1 n-9)$. There was significantly more eicosenoic acid in the high cortisol group compared with the low cortisol group, but their overall prevalence was small. The content of saturated FAs (SAFAs) in the TAG-rich lipids was close to the level of MUFAs in mass proportions. Of the SAFA's, palmitic acid, (16:0) was most abundant followed by stearic (18:0), myristic (14:0) and lauric (12:0) acids (Table 2). Higher cortisol level in breast milk was associated with lower 16:0 $(U=943, p=0.03)$ but with higher proportion of lauric (12:0) $(\mathrm{t}=-3.7, \mathrm{df}=98, p=0.001)$ and myristic (14:0) acids $(t=-2.6, \mathrm{df}=98, p=0.02)$ in the TAG-rich fraction of lipids. The linear regression analyses showed that after controlling for pre-pregnancy, BMI and sampling time, milk cortisol was shown to be significant for 
Table 3 Fatty acid compositions of phospholipid-rich lipids in human milk

\begin{tabular}{|c|c|c|c|c|c|c|c|c|c|c|}
\hline \multirow[t]{3}{*}{ Fatty acid } & \multicolumn{5}{|c|}{ Relative mass proportions in phospholipid-rich lipids } & \multicolumn{5}{|c|}{ Quantities as phosphatidylcholine ( $\mathrm{mg} / \mathrm{mL})$} \\
\hline & \multicolumn{2}{|c|}{$\begin{array}{l}\text { Low cortisol }(<3 \\
\text { nmol/L) }\end{array}$} & \multicolumn{2}{|c|}{$\begin{array}{l}\text { High cortisol (> } 10 \\
\mathrm{nmol} / \mathrm{L})\end{array}$} & \multirow[t]{2}{*}{ p-value } & \multicolumn{2}{|c|}{$\begin{array}{l}\text { Low cortisol }(<3 \\
\mathrm{nmol} / \mathrm{L})\end{array}$} & \multicolumn{2}{|c|}{$\begin{array}{l}\text { High cortisol (> } 10 \\
\mathrm{nmol} / \mathrm{L})\end{array}$} & \multirow[t]{2}{*}{$\begin{array}{l}\mathrm{p}^{-} \\
\text {value }\end{array}$} \\
\hline & $\overline{M e a n}$ & STDEV & Mean & STDEV & & Mean & STDEV & Mean & STDEV & \\
\hline Lauric 12:0 & 2.16 & 1.04 & 2.50 & 1.38 & $0.29^{\mathrm{a}}$ & 0.03 & 0.02 & 0.03 & 0.02 & $0.63^{\mathrm{a}}$ \\
\hline Myristic 14:0 & 4.01 & 1.38 & 4.87 & 1.77 & $0.01^{\mathrm{a}, \mathrm{b}}$ & 0.05 & 0.03 & 0.05 & 0.03 & $0.37^{\mathrm{a}}$ \\
\hline Myristoleic $14: 1 n-5$ & 0.16 & 0.11 & 0.16 & 0.09 & $0.99^{\mathrm{a}}$ & 0.002 & 0.002 & 0.002 & 0.001 & $0.59^{\mathrm{a}}$ \\
\hline Palmitic 16:0 & 21.55 & 3.04 & 21.70 & 3.25 & $0.81^{c}$ & 0.23 & 0.14 & 0.21 & 0.10 & $0.96^{\mathrm{a}}$ \\
\hline Palmitoleic $16: 1 n-7$ & 1.96 & 0.63 & 1.88 & 0.70 & $0.57^{c}$ & 0.02 & 0.02 & 0.02 & 0.01 & $0.53^{\mathrm{a}}$ \\
\hline Stearic 18:0 & 13.20 & 4.14 & 13.07 & 3.83 & $0.81^{\mathrm{a}}$ & 0.12 & 0.06 & 0.12 & 0.05 & $0.52^{\mathrm{a}}$ \\
\hline Oleic 18:1n-9 & 31.30 & 6.62 & 30.13 & 5.98 & $0.23^{\mathrm{a}}$ & 0.37 & 0.29 & 0.32 & 0.20 & $0.61^{\mathrm{a}}$ \\
\hline Vaccenic $18: 1 n-7$ & 1.68 & 0.32 & 1.63 & 0.34 & $0.43^{c}$ & 0.02 & 0.02 & 0.02 & 0.01 & $0.58^{\mathrm{a}}$ \\
\hline Linoleic $18: 2 n-6$ & 14.81 & 2.68 & 14.94 & 2.72 & $0.77^{\mathrm{a}}$ & 0.15 & 0.09 & 0.15 & 0.07 & $0.69^{a}$ \\
\hline Linolenic $18: 3 n-3$ & 1.44 & 0.58 & 1.49 & 0.57 & $0.98^{\mathrm{a}}$ & 0.02 & 0.02 & 0.02 & 0.01 & $0.77^{\mathrm{a}}$ \\
\hline Arachidic 20:0 & 0.18 & 0.08 & 0.19 & 0.07 & $0.69^{a}$ & 0.002 & 0.001 & 0.002 & 0.001 & $0.81^{\mathrm{a}}$ \\
\hline Gondoic 20:1n - 9 & 0.63 & 0.16 & 0.65 & 0.15 & $0.37^{\mathrm{a}}$ & 0.007 & 0.004 & 0.006 & 0.004 & $0.88^{\mathrm{a}}$ \\
\hline Eicosadienoic 20:2n-6 & 0.30 & 0.07 & 0.33 & 0.07 & $0.06^{c}$ & 0.003 & 0.002 & 0.003 & 0.002 & $0.89^{a}$ \\
\hline Dihomogammalinolenic 20:3n-6 & 0.85 & 0.32 & 0.86 & 0.33 & $0.98^{\mathrm{a}}$ & 0.008 & 0.004 & 0.008 & 0.004 & $0.52^{\mathrm{a}}$ \\
\hline Arachidonic 20:4n-6 & 1.83 & 0.79 & 1.92 & 0.99 & $0.90^{\mathrm{a}}$ & 0.02 & 0.01 & 0.02 & 0.01 & $0.70^{\mathrm{a}}$ \\
\hline Eicosatrienoic $20: 3 n-3$ & 0.02 & 0.04 & 0.01 & 0.04 & $0.27^{\mathrm{a}}$ & 0.000 & 0.001 & 0.000 & 0.001 & $0.22^{\mathrm{a}}$ \\
\hline Eicosapentaenoic 20:5n - 3 & 0.29 & 0.16 & 0.26 & 0.15 & $0.26^{\mathrm{a}}$ & 0.003 & 0.002 & 0.003 & 0.002 & $0.29^{\mathrm{a}}$ \\
\hline Behenic 22:0 & 0.03 & 0.04 & 0.03 & 0.04 & $0.93^{\mathrm{a}}$ & 0.000 & 0.001 & 0.000 & 0.001 & $0.93^{\mathrm{a}}$ \\
\hline Docosenoic 22:1n - 9 & 0.11 & 0.08 & 0.17 & 0.11 & $\mathbf{0 . 0 0 9 ^ { a , b }}$ & 0.001 & 0.001 & 0.001 & 0.001 & $0.11^{a}$ \\
\hline Nervonic 24:1n-9 & 1.02 & 0.69 & 0.92 & 0.39 & $0.93^{\mathrm{a}}$ & 0.01 & 0.01 & 0.01 & 0.01 & $0.48^{\mathrm{a}}$ \\
\hline Docosahexaenoic $22: 6 n-3$ & 0.05 & 0.33 & 0.06 & 0.28 & $0.69^{\mathrm{a}}$ & 0.000 & 0.001 & 0.000 & 0.001 & $0.71^{\mathrm{a}}$ \\
\hline Other fatty acids & 2.43 & 0.81 & 2.24 & 0.70 & $0.11^{\mathrm{a}}$ & 0.03 & 0.02 & 0.02 & 0.01 & $0.50^{\mathrm{a}}$ \\
\hline SAFA & 41.13 & 5.01 & 42.37 & 5.15 & $0.23^{c}$ & 0.43 & 0.25 & 0.41 & 0.18 & $0.99^{a}$ \\
\hline MUFA & 35.83 & 7.17 & 34.62 & 6.50 & $0.20^{\mathrm{a}}$ & 0.43 & 0.33 & 0.37 & 0.22 & $0.61^{\mathrm{a}}$ \\
\hline PUFA & 19.59 & 3.63 & 19.86 & 3.67 & $0.53^{\mathrm{a}}$ & 0.20 & 0.12 & 0.19 & 0.10 & $0.72^{\mathrm{a}}$ \\
\hline Omega-3 FAs & 1.80 & 0.63 & 1.82 & 0.61 & $0.89^{a}$ & 0.02 & 0.02 & 0.02 & 0.01 & $0.70^{\mathrm{a}}$ \\
\hline Omega-6 FAs & 17.79 & 3.54 & 18.04 & 3.51 & $0.52^{\mathrm{a}}$ & 0.18 & 0.10 & 0.17 & 0.09 & $0.65^{a}$ \\
\hline
\end{tabular}

Relative mass proportion of polar lipids from all lipids

$$
\begin{array}{lllll}
3.28 & 1.43 & 2.89 & 1.19 & 0.16^{\mathrm{a}}
\end{array}
$$

Data is presented as relative proportions $(\%)$ and quantities $(\mathrm{mg} / \mathrm{mL})$ and grouped based on milk cortisol levels. Statistically significant differences $(\mathrm{p}<0.05)$ between low and high milk cortisol groups are highlighted with bold type. Abbreviations: STDEV standard deviation, SAFA saturated fatty acids, MUFA monounsaturated fatty acids, PUFA polyunsaturated fatty acids

${ }^{\text {a }}$ Significant difference between the low and high cortisol groups, Mann-Whitney $U$ test

${ }^{b}$ Milk cortisol (as continuous variable) remained a statistically significant predictor after controlling for pre-pregnancy BMI and sampling time in linear regression analysis, see Additional file 1

c Significant difference between the low and high cortisol groups, T-test ( $d f=98)$

lauric acid (12:0) (mass \%: $\beta=0.38, p=0.000 ; \mathrm{mg} / \mathrm{mL}: \beta=$ $0.32, p=0.003)$ and myristic acid (14:0) (mass \%: $\beta=0.26$, $p=0.01 ; \mathrm{mg} / \mathrm{mL}: \beta=0.27, \mathrm{p}=0.01)$ in TAG-rich lipids [Additional file 1].

There were no differences in the mass proportions of total PUFAs or in the proportions of individual PUFAs between the cortisol groups (Table 2). The most abundant PUFA among the TAG-rich lipids was linoleic acid
$(18: 2 n-6)$. The ratio of omega- 6 FAs and omega- 3 FAs in TAG-rich fraction did not differ between the groups.

PUFAs were more abundant in the PL-rich fraction than in the TAG-rich fraction (Table 3). The most abundant individual PUFAs in the PL-rich fraction were linoleic acid $(18: 2 n-6)$ followed by arachidonic acid (20:4n -6). In the PL-rich fraction, higher cortisol was associated with higher myristic acid (14:0) (mass \%; $U=887$, 
$p=0.01)$ and 22:1n-9 (mass \%; $U=873, p=0.009$ ) (Table 3). After controlling for pre-pregnancy BMI and sampling time in linear regression, milk cortisol was shown to be significant for myristic acid (14:0) (mass \%; $\beta=0.23, p=0.03$ ) and 22:1n-9 (mass \%; $\beta=0.23, p=$ 0.03 ) in PL-rich lipids [Additional file 1]. The ratio of omega-6 FAs and omega-3 FAs in the PL-rich fraction did not differ between the groups. Cortisol did not cause grouping in the PCA models with all of the measured lipids [Additional file 2].

\section{Separation of phospholipids in principal component analysis}

In the principal component model with mass \% data of PL-rich fraction, a group of 12 samples separated, but the separation was not associated with the milk cortisol [Additional file 3]. Based on the PCA correlation loadings, these samples were associated with a higher proportion of polyunsaturated fatty acids (especially those of belonging to the $n-6$ series) and stearic acid (18:0).

\section{Discussion}

Associations between cortisol concentrations and lipids in milk

Because glucocorticoids are known to take part in the regulation of lipid metabolism [6], this study investigated the associations between cortisol concentrations and lipid content and composition in human milk. Our findings were in agreement with an earlier report [25] that showed no correlation between milk glucocorticoids and total milk fat content. However, our study revealed that the influence of cortisol can be seen, when the composition of individual FAs in milk is investigated. Our study included milk samples with pre-identified low- and high cortisol concentrations. The composition of these milks differed in the abundance of lauric (12:0) and myristic (14:0) acids, with the high cortisol group having a higher prevalence and concentration of these FAs. This points to cortisol's influence in the release of medium- and intermediate chain FAs from maternal body stores $[6$, 36]. Alternatively, these FAs may originate from endogenous de novo synthesis possibly indicating a high carbohydrate to lipid ratio in the mother's diet [10, 37] or a high consumption of dairy fat where these FAs are abundant [20]. Lauric acid, as a medium-chain FA, provides rapidly available energy for the infant. We also found that lower milk cortisol level was associated with a higher proportion of palmitic acid (16:0), but this association was not significant when the model was adjusted for BMI and sampling time. The overall quantity of palmitic acid is important for the infant's total energy intake, and its positioning in the glycerol backbone is of special importance to the infant. This is because palmitic acid released from the primary positions of the triacylglycerol backbone form insoluble calcium soaps, which are lost to feces and can harden the consistency of stools [37, 38]. Previously, minor monounsaturated FAs have been increased in the neural tissues of mice after dietary EPA and DHA feeding, and the authors concluded that their role in cognition should be investigated [39]. In this study, the proportion of eicosenoic acid in the breast milk was associated with higher cortisol levels, but the overall quantity or proportion in the milk was low in both groups investigated here, and the difference was not significant when adjusting the model with BMI and sampling time. However, our results point towards the need of further research also in the minor FAs such as eicosenoic and docosenoic acids.

\section{Association between cortisol and energy metabolism}

Cortisol and obesity appear to be linked [40], as obesity is characterized by increased secretion of glucocorticoids $[40,41]$ and chronic exposure to glucocorticoids induces lipogenesis, resulting in increased fat storage and in particular, abdominal adiposity [7]. On the other hand, glucocorticoids in human milk reflect their circulating abundance in the maternal blood and saliva [42] and might play a role in the metabolic programming of the infant [43]. The fact that breastfed children exhibit $40 \%$ greater salivary cortisol than formula-fed children may indicate that the cortisol of milk is effectively absorbed into the infant's circulatory system [44]. Previously, milk cortisone has been detected to be significantly higher in normal weight mothers compared to overweight and underweight women, but for cortisol no difference was seen [45]. In our study, low cortisol was associated with higher pre-pregnancy BMI. However, the average prepregnancy BMI of the mothers in our study was normal or very close to normal in both groups $(25.12 \pm 3.77$ vs. $23.68 \pm 4.47$ ), and unfortunately, we had no information on BMI across pregnancy. After adjusting for prepregnancy BMI and milk sampling time, the association between milk cortisol and lauric and myristic acids in triacylglycerol-rich lipids, and myristic and docosenoic acid in phospholipid-rich lipids remained significant. Cortisol exposure through human milk may help to program metabolic functioning and influence the risk of childhood obesity via modulation of later glucocorticoid metabolism [46]. Infants exposed to higher milk cortisol levels at 3 months were less likely to exhibit BMI gains over the first 2 years of life, compared with infants exposed to lower milk cortisol, indicating that some level of cortisol exposure might be beneficial for developing healthy weight later [47]. This indicates that glucocorticoid exposure through human milk might have more complex effects on the development of obesity than systemic cortisol concentrations [48]. 
The effect of the composition of a single meal (mostly high protein vs. high carbohydrate) on cortisol has been previously studied, and the results vary from no effect $[49,50]$ to a higher response to a carbohydrate meal [51]. Some dietary supplements have been noted to affect steroid hormone homeostasis, as previously reviewed [52]. Examples of such supplements include the amino acid tryptophan [53] as well as phosphatidylserine and phosphatidic acid [54]. However, it is not clear whether these are relevant as part of a balanced diet. However, future studies investigating the effect of cortisol on human milk lipids would benefit from the assessment of the mother's dietary profiles.

\section{Effect of polar membrane lipids in milk}

The effect of polar membrane lipids is likely to extend beyond the content of long-chain PUFAs in them [26]. Previously, it has been shown that supplementation of the milk-fat globule membrane preparations to formulafed infants has reduced the episodes of diarrhea [55] and has positively affected the cognitive score of the infants at the age of 12 [56]. In chronically stressed adult men, bovine milk based PLs have a delayed decline from peak levels in morning salivary cortisol and attenuated stressinduced memory impairments [57]. In our study, no correlation was found between the total amount of phospholipids in milk and milk cortisol. The conserved levels of phospholipids in human milk might be an indication of not only a certain conserved milk fat globule size but also of the importance of the globule membrane on the well-being and development of the infant.

\section{Effect of infant sex on milk composition}

Previously, infant sex has been reported to affect milk energy density in macaque and human mothers $[23,58,59]$. In this study, no association between infant sex and the total amount of lipids or cortisol in the human milk was detected. The interaction between infant sex and milk cortisol has been shown to affect infant developmental outcomes as higher milk cortisol has been related to a higher infant fear reactivity in girls but not in boys [14]. Cortisol has also been linked with infant negative emotional reactivity, especially fear reactivity and sadness [33]. In addition, associations between postnatal glucocorticoid exposure and enhanced learning in rodents have been reported $[60,61]$ thus indicating the need for further research in the area of milk cortisol in relation to infant development.

\section{Strengths and limitations}

This study had several strengths. The analyses of human milk lipids separately in the triacylglycerol-rich and phospholipid-rich fractions provided an indication of storage and membrane lipids, separately. Furthermore, the background data on the mother-infant dyads from the larger FinnBrain Birth Cohort Study utilized here were quite extensive. However, this study was limited in the number of hormones accounted for. While both cortisone and cortisol can be detected in milk, we chose to concentrate on milk cortisol, because it is more active than cortisone and has direct links with energy metabolism. Also, the present milk samples originated from an individual time point. The amount of cortisol in breast milk has been observed to be influenced by the time of the day of sampling and thus the use of frequent samples from all nursing occasions and calculations of an area under the cortisol curve would be feasible [42]. However, as our aim was to study the interrelationships between milk cortisol and milk lipids instead of overall cortisol exposure of the infants, and we used a regression model to adjust for sampling time that justified the use of an individual time point.

\section{Conclusions}

Human breast milk represents one of the key early biological exposures for the developing child, including bioactive compounds like cortisol and fatty acids. Breast milk contains numerous bioactive molecules that take part at least in the protection against infections and inflammation, intestinal microbial colonization and contribute to organ, including neural, development [62]. The results of this study shed light in understanding the correlations between two bioactive components, namely the content and composition of lipids and cortisol. This study revealed small but significant associations between individual fatty acids of human milk and milk cortisol, indicating that cortisol might be one of the factors affecting the origin of the lipids in human milk. Such an association has not emerged, when only total fat content has been assessed. Thus milk cortisol might be one of the factors regulating the lipid composition in human milk but not necessarily its total lipid content. The principal component separation of phospholipid-rich lipids warrants further investigation of such minor but important components of human breast milk.

\section{Supplementary information}

Supplementary information accompanies this paper at https://doi.org/10. 1186/s13006-020-00307-7.

Additional file 1: Supplementary Table 1. Linear regression analysis. Additional file 2: Supplementary Figure 1. Principal component analysis model with all mothers $(n=100)$ and all measured lipids.

Additional file 3: Supplementary Figure 2. Principal component analysis model of phospholipid fatty acids.

Abbreviations

BMI: Body mass index; FA: Fatty acid; MUFA: Monounsaturated fatty acid; TAG: Triacylglycerol; PL: Phospholipid; PUFA: Polyunsaturated fatty acid; SAFA: Saturated fatty acid 


\section{Acknowledgements}

We thank the families for participating in the FinnBrain Birth Cohort Study. The FinnBrain staff and assisting personnel, Johanna Ravaska, Merena Grönholm, Eija Jossandt, Farhia Mohammed and Katja Tervahartiala are acknowledged for their invaluable efforts for the logistics of the project. Sirpa Hyttinen from the Finnish Institute for Health and Welfare is acknowledged for her work on the milk cortisol assays. Annamari Kumpulainen, Ella Muhli, Tiina Pasma and Aino Tarkkio from Food Chemistry and Food Development, University of Turku, Finland, are thanked for technical assistance in the lipid analysis. Dr. Oskar Laaksonen is thanked for assistance with the multivariate models and Juho Pelto for the statistical consultation. Robert M. Badeau, M.Sc., Ph.D. (www.auraenglish.com) is thanked for reviewing the English language of the manuscript.

\section{Conflict of interest}

The authors declare no conflict of interest.

\section{Authors' contributions}

All authors read and approved the final manuscript.

\section{Funding}

Finnbrain Birth Cohort Study (HK) has been funded by the Academy of Finland (grant numbers 253270, 134950), the Jane and Aatos Erkko Foundation as well as the Signe and Ane Gyllenberg Foundation. The analysis of the fatty acid compositions was funded by Food Chemistry and Food Development, University of Turku, Finland.

\section{Availability of data and materials}

The datasets analyzed during the current study are available from the corresponding author on a reasonable request.

\section{Ethics approval and consent to participate}

The study protocols were approved by The Joint Ethics Committee of University of Turku and Turku University Hospital (Breastfeeding study: 17.2.2013 §88 ETMK 121/1801/2013). All participants provided written informed consent.

\section{Consent for publication}

Not applicable as the manuscript does not contain data from any individual person.

\section{Competing interests}

The authors declare that they have no competing interests.

\section{Author details}

'Department of Biochemistry, Food Chemistry and Food Development, University of Turku, Itäinen Pitkäkatu 4C, Fl-20014 Turun yliopisto, Turku, Finland. ${ }^{2}$ The FinnBrain Birth Cohort Study, Turku Brain and Mind Center, Institute of Clinical Medicine, University of Turku, Turku, Finland. ${ }^{3}$ Department of Child Psychiatry, Turku University Hospital and University of Turku, Turku, Finland. ${ }^{4}$ Department of Psychiatry, Turku University Hospital and University of Turku, Turku, Finland.

Received: 30 September 2019 Accepted: 9 July 2020

Published online: 20 July 2020

\section{References}

1. Vicennati V, Garelli S, Rinaldi E, Di Dalmazi G, Pagotto U, Pasquali R. Crosstalk between adipose tissue and the HPA axis in obesity and overt hypercortisolemic states. Horm Mol Biol Clin Investig. 2014;17:63-77.

2. Sapolsky RM, Romero LM, Munck AU. How do glucocorticoids influence stress responses? Integrating permissive, suppressive, stimulatory, and preparative actions. Endocr Rev. 2000;21:55-89.

3. Khani S, Tayek JA. Cortisol increases gluconeogenesis in humans: its role in the metabolic syndrome. Clin Sci (Lond). 2001;101:739-47.

4. Peckett AJ, Wright DC, Riddell MC. The effects of glucocorticoids on adipose tissue lipid metabolism. Metabolism. 2011;60:1500-10.

5. Macfarlane DP, Forbes S, Walker BR. Glucocorticoids and fatty acid metabolism in humans: fuelling fat redistribution in the metabolic syndrome. J Endocrinol. 2008;197:189-204.
6. Lee M, Pramyothin P, Karastergiou K, Fried SK. Deconstructing the roles of glucocorticoids in adipose tissue biology and the development of central obesity. Biophys Acta - Mol Basis Dis. 1842;2014:473-81.

7. John K, Marino JS, Sanchez ER, Hinds TD. The glucocorticoid receptor: cause of or cure for obesity? Am J Physiol Endocrinol Metab. 2016;310:249.

8. Bauer ME, Teixeira AL. Inflammation in psychiatric disorders: what comes first? Ann N Y Acad Sci. 2019;1437:57-67.

9. Field T. Prenatal anxiety effects: a review. Infant Behav Dev. 2017:49:120-8.

10. Hascoët JM, Chauvin M, Pierret C, Skweres S, Egroo LV, Rouge C, et al. Impact of maternal nutrition and perinatal factors on breast milk composition after premature delivery. Nutrients. 2019;11:366.

11. Patacchioli FR, Cigliana G, Cilumbriello A, Perrone G, Capri O, Alemá GS, et al. Maternal plasma and milk free cortisol during the first 3 days of breast-feeding following spontaneous delivery or elective cesarean section. Gynecol Obstet Investig. 1992;34:159-63.

12. Hollanders JJ, Heijboer AC, van der Voorn B, Rotteveel J, Finken MJJ. Nutritional programming by glucocorticoids in breast milk: targets, mechanisms and possible implications. Best Pract Res Clin Endocrinol Metab. 2017:31:397-408.

13. Cottrell EC, SeckI JR. Prenatal stress, glucocorticoids and the programming of adult disease. Front Behav Neurosci. 2009;3:19.

14. Nolvi S, Uusitupa HM, Bridgett DJ, Pesonen H, Aatsinki AK, Kataja EL, et al. Human milk cortisol concentration predicts experimentally induced infant fear reactivity: moderation by infant sex. Dev Sci. 2018;21:e12625.

15. Theiler-Schwetz V, Zaufel A, Schlager H, Obermayer-Pietsch B, Fickert $P$, Zollner G. Bile acids and glucocorticoid metabolism in health and disease. Biochim Biophys Acta Mol basis Dis. 1865;2019:243-51.

16. Gomez-Gallego C, Kumar H, Garcia-Mantrana I, du Toit E, Suomela JP, Linderborg KM, et al. Breast milk polyamines and microbiota interactions: impact of mode of delivery and geographical location. Ann Nutr Metab. 2017;70:184-90.

17. Kumar H, du Toit E, Kulkarni A, Aakko J, Linderborg KM, Zhang Y, et al. Distinct patterns in human milk microbiota and fatty acid profiles across specific geographic locations. Front Microbiol. 2016;7:1619.

18. Bravi F, Wiens F, Decarli A, Dal Pont A, Agostoni C, Ferraroni M. Impact of maternal nutrition on breast-milk composition: a systematic review. Am J Clin Nutr. 2016;104:646-62.

19. Ballard O, Morrow AL. Human milk composition: nutrients and bioactive factors. Pediatr Clin N Am. 2013;60:49-74.

20. Mäkelä J, Linderborg K, Niinikoski H, Yang B, Lagström H. Breast milk fatty acid composition differs between overweight and normal weight women: the STEPS study. Eur J Nutr. 2013:52:727-35.

21. Saarela T, Kokkonen J, Koivisto M. Macronutrient and energy contents of human milk fractions during the first six months of lactation. Acta Paediatr. 2005;94:1176-81.

22. Al-Tamer YY, Mahmood AA. The influence of Iraqi mothers' socioeconomic status on their milk-lipid content. Eur J Clin Nutr. 2006;60:1400-5.

23. Powe $C E$, Knott $C D$, Conklin-Brittain N. Infant sex predicts breast milk energy content. Am J Hum Biol. 2010;22:50-4.

24. Sullivan EC, Hinde K, Mendoza SP, Capitanio JP. Cortisol concentrations in the milk of rhesus monkey mothers are associated with confident temperament in sons, but not daughters. Dev Psychobiol. 2011;53:96-104.

25. Hollanders JJ, Kouwenhoven SMP, van der Voorn B, van Goudoever JB, Rotteveel J, Finken MJJ. The association between breastmilk glucocorticoid concentrations and macronutrient contents throughout the day. Nutrients. 2019;11:259.

26. Demmelmair $\mathrm{H}$, Koletzko B. Variation of metabolite and hormone contents in human milk. Clin Perinatol. 2017:44:151-64.

27. Rudolph MC, Neville MC, Anderson SM. Lipid synthesis in lactation: diet and the fatty acid switch. J Mammary Gland Biol Neoplasia. 2007;12:269-81.

28. Carlson SE, Colombo J. Docosahexaenoic acid and arachidonic acid nutrition in early development. Adv Pediatr Infect Dis. 2016;63:453-71.

29. Koletzko B. Human Milk Lipids. Ann Nutr Metab. 2016;69:28-40.

30. Hadley KB, Ryan AS, Forsyth S, Gautier S, Salem N Jr. The essentiality of arachidonic acid in infant development. Nutrients. 2016;8:216.

31. Jensen DR, Bessesen DH, Etienne J, Eckel RH, Neville MC. Distribution and source of lipoprotein lipase in mouse mammary gland. J Lipid Res. 1991;32: 733-42.

32. Karlsson L, Tolvanen M, Scheinin NM, Uusitupa HM, Korja R, Ekholm E, et al. Cohort Profile: The FinnBrain Birth Cohort Study (FinnBrain). Int J Epidemiol. 2018;47:15-16j. 
33. Grey KR, Davis EP, Sandman CA, Glynn LM. Human milk cortisol is associated with infant temperament. Psychoneuroendocrinology. 2013;38: $1178-85$.

34. Folch J, Lees M, Stanley G. A simple method for the isolation and purification of total lipides from animal tissues. J Biol Chem. 1957;226:497509.

35. Christie W, Han X. Lipid analysis. Isolation, separation, identification and lipidomic analysis. $4^{\text {th }}$ ed. Bridgewater: The Oily Press; 2010.

36. Djurhuus CB, Gravholt CH, Nielsen S, Pedersen SB, Moller N, Schmitz O. Additive effects of cortisol and growth hormone on regional and systemic lipolysis in humans. Am J Physiol Endocrinol Metab. 2004;286:488.

37. Demmelmair H, Koletzko B. Lipids in human milk. Best Pract Res Clin Endocrinol Metab. 2018;32:57-68.

38. Petit V, Sandoz L, Garcia-Rodenas CL. Importance of the regiospecific distribution of long-chain saturated fatty acids on gut comfort, fat and calcium absorption in infants. Prostaglandins Leukot Essent Fatty Acids. 2017:121:40-51.

39. Valentini KJ, Pickens CA, Wiesinger JA, Fenton J. The effect of fish oil supplementation on brain DHA and EPA content and fatty acid profile in mice. Int J Food Sci Nutr. 2018;69:705-17.

40. Bose M, Olivan B, Laferrere B. Stress and obesity: the role of the hypothalamic-pituitary-adrenal axis in metabolic disease. Curr Opin Endocrinol Diabetes Obes. 2009;16:340-6.

41. Stewart PM, Boulton A, Kumar S, Clark PM, Shackleton CH. Cortisol metabolism in human obesity: impaired cortisone $\rightarrow$ cortisol conversion in subjects with central adiposity. J Clin Endocrinol Metab. 1999;84:1022-7.

42. van der Voorn B, de Waard M, van Goudoever JB, Rotteveel J, Heijboer AC, Finken MJ. Breast-milk cortisol and cortisone concentrations follow the diurnal rhythm of maternal hypothalamus-pituitary-adrenal axis activity. J Nutr. 2016;146:2174-9.

43. Dettmer AM, Murphy AM, Guitarra D, Slonecker E, Suomi SJ, Rosenberg KL, et al. Cortisol in neonatal mother's milk predicts later infant social and cognitive functioning in rhesus monkeys. Child Dev. 2018;89:525-38.

44. Cao Y, Rao SD, Phillips TM, Umbach DM, Bernbaum JC, Archer Jl, et al. Are breast-fed infants more resilient? Feeding method and cortisol in infants. J Pediatr. 2009:154:452-4.

45. Pundir S, Makela J, Nuora A, Junttila N, Wall CR, Linderborg K, et al. Maternal influences on the glucocorticoid concentrations of human milk: the STEPS study. Clin Nutr. 2018;38:1913-20.

46. Caulfield Jl, Cavigelli SA. Individual differences in glucocorticoid regulation: does it relate to disease risk and resilience? Front Neuroendocrinol. 2020;56: 100803 Jasmine I Caulfield 1, Sonia A Cavigelli 2.

47. Hahn-Holbrook J, Le TB, Chung A, Davis EP, Glynn LM. Cortisol in human milk predicts child BMI. Obesity (Silver Spring). 2016:24:2471-4.

48. Veldhorst MA, Noppe G, Jongejan MH, Kok CB, Mekic S, Koper JW, et al. Increased scalp hair cortisol concentrations in obese children. J Clin Endocrinol Metab. 2014:99:285-90.

49. Lemmens SG, Born JM, Martens EA, Martens MJ, Westerterp-Plantenga MS. Influence of consumption of a high-protein vs high-carbohydrate meal on the physiological cortisol and psychological mood response in men and women. PLoS One. 2011;6:e16826.

50. Bray GA, Most M, Rood J, Redmann S, Smith SR. Hormonal responses to a fast-food meal compared with nutritionally comparable meals of different composition. Ann Nutr Metab. 2007;51:163-71.

51. Martens MJI, Rutters F, Lemmens SGT, Born JM, Westerterp-Plantenga MS. Effects of single macronutrients on serum cortisol concentrations in normal weight men. Physiol Behav. 2010;101:563-7.

52. Stachowicz M, Lebiedzińska A. The effect of diet components on the level of cortisol. Eur Food Res Technol. 2016;242:2001-9.

53. Capello AEM, Markus CR. Effect of sub chronic tryptophan supplementation on stress-induced cortisol and appetite in subjects differing in 5-HTTLPR genotype and trait neuroticism. Psychoneuroendocrinology. 2014;45:96-107.

54. Hellhammer J, Vogt D, Franz N, Freitas U, Rutenberg D. A soy-based phosphatidylserine/ phosphatidic acid complex (PAS) normalizes the stress reactivity of hypothalamus-pituitary-adrenal-axis in chronically stressed male subjects: a randomized, placebo-controlled study. Lipids Health Dis. 2014;13:121.

55. Zavaleta N, Kvistgaard AS, Graverholt G, Respicio G, Guija H, Valencia N, et al. Efficacy of an MFGM-enriched complementary food in diarrhea, anemia, and micronutrient status in infants. J Pediatr Gastroenterol Nutr. 2011;53:561-8.
56. Timby N, Domellof E, Hernell O, Lonnerdal B, Domellof M. Neurodevelopment, nutrition, and growth until 12 mo of age in infants fed a low-energy, low-protein formula supplemented with bovine milk fat globule membranes: a randomized controlled trial. Am J Clin Nutr. 2014;99: 860-8.

57. Schubert M, Contreras C, Franz N, Hellhammer J. Milk-based phospholipids increase morning cortisol availability and improve memory in chronically stressed men. Nutr Res. 2011;31:413-20.

58. Fujita M, Roth E, Lo YJ, Hurst C, Vollner J, Kendell A. In poor families, mothers' milk is richer for daughters than sons: a test of Trivers-Willard hypothesis in agropastoral settlements in northern Kenya. Am J Phys Anthropol. 2012;149:52-9.

59. Hinde K. Richer milk for sons but more milk for daughters: sex-biased investment during lactation varies with maternal life history in rhesus macaques. Am J Hum Biol. 2009;21:512-9.

60. Casolini P, Cigliana G, Alema GS, Ruggieri V, Angelucci L, Catalani A. Effect of increased maternal corticosterone during lactation on hippocampal corticosteroid receptors, stress response and learning in offspring in the early stages of life. Neuroscience. 1997;79:1005-12.

61. Catalani A, Casolini P, Cigliana G, Scaccianoce S, Consoli C, Cinque C, et al. Maternal corticosterone influences behavior, stress response and corticosteroid receptors in the female rat. Pharmacol Biochem Behav. 2002; 73:105-14.

62. Andreas NJ, Kampmann B, Mehring L-DK. Human breast milk: a review on its composition and bioactivity. Early Hum Dev. 2015;91:629-35.

\section{Publisher's Note}

Springer Nature remains neutral with regard to jurisdictional claims in published maps and institutional affiliations.
Ready to submit your research? Choose BMC and benefit from:

- fast, convenient online submission

- thorough peer review by experienced researchers in your field

- rapid publication on acceptance

- support for research data, including large and complex data types

- gold Open Access which fosters wider collaboration and increased citations

- maximum visibility for your research: over $100 \mathrm{M}$ website views per year

At BMC, research is always in progress.

Learn more biomedcentral.com/submissions 